\title{
Teorías e Investigación de la Comunicación en América Latina. Situación Actual
}

\author{
Dr. M.C. Gustavo A. León Duarte \\ Profesor Investigador del Departamento de Ciencias \\ de la Comunicación de la Universidad de Sonora, México
}

RESUMEN

El presente ensayo tiene por objeto describir y analizar las principales corrientes teóricas de la comunicación en América Latina a partir de dos aspectos centrales: por un lado, del estado actual de la investigación y producción que sobre el tema existe en algunos países de Latinoamérica y, por otro, del sentido que ha marcado, desde principios de la última década, la reforma curricular en las escuelas de comunicación en América Latina y, consecuentemente, en la definición del objeto de estudio de la comunicación.

A partir de la década de los noventa, la aplicación académica y la investigación de la teoría de la comunicación en América latina ha experimentado un cambio renovador, saludable y de necesaria superación. Este cambio inicia principalmente a partir de la superación de la decadente tendencia a adscribir los estudios de la comunicación a una sola disciplina e ir creando una conciencia creciente de su estatuto transdiciplinar y de revolucionar las formas de análisis y abordajes de la producción, difusión y recepción del mensaje. Estos cambios, precisamente, fundamentan la principal corriente teórica y de investigación de la comunicación en Latinoamérica: los estudios culturales.

\section{ABSTRACT}

The present essay intends to describe and to analyze the main theoretical currents of communication in Latin America from two central aspects: on one hand, the current state of research and production that on the subject exists in some Latin American countries and, on the other hand, the sense that has marked, the beginnings of the last decade, the curricular reform in the schools of communication in Latin America and, consequently, the definition of the object of study of communication.

As of the Nineties, the academic application and research of the theory of communication in Latin America have experienced a healthful change and of necessary overcoming. This change mainly initiates from the overcoming of the declining tendency that assigns the studies of communication into a discipline. This has created an increasing conscience of its transdiciplinar statute and revolutionizes the forms of analysis of the production, diffusion and reception of the message. These changes are the base of the main theoretical current and communication research on Latin America: cultural studies.

Palabras claves: Teorías de la comunicación/corrientes y enfoques de la comunicación/Estatuto transdisciplinar/Estudios culturales/Producción/Análisis/Recepción del mensaje.

Key Words: Theories of the communication/Currents and approaches of communication/Transdisciplinar statute/Cultural studies/Production/Analysis and reception of the message.

\section{Introducción}

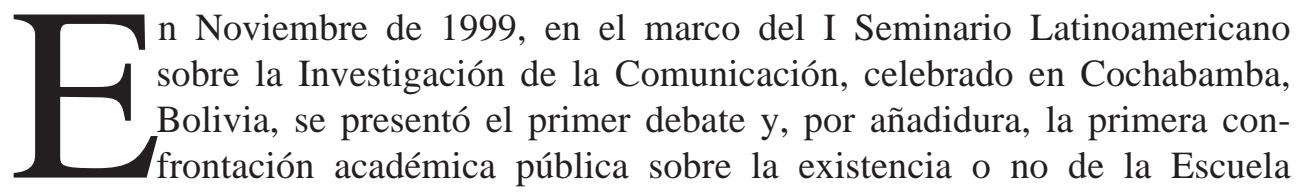


Latinoamericana de Comunicación ${ }^{1}$. Aún cuando el debate fue abierto por el Dr. Jesús Martín Barbero al convocar a la audiencia a negociar con la globalización para insertar en ella sus proyectos, en realidad fue el Dr. José Marques de Melo, Director de la cátedra "UNESCO Comunicación para el Desarrollo en Brasil" e impulsor de la recuperación y sistematización del pensamiento comunicacional latinoamericano, el que efectuó un recuento panorámico de las fases y los autores por las que atravesó lo que él considera dicha Escuela, cuya memoria está contribuyendo a organizar desde hace ya varios años². Para Marques de Melo, ésta se caracteriza por su mestizaje teórico, su hibridismo metodológico, su compromiso ético-político y su dimensión extranacional. La confrontación, empero, fue abierta por el Dr. Guillermo Orozco Gómez, impulsor de los estudios cualitativos sobre recepción en México, al poner en duda la posibilidad de hablar de una Escuela, pues conllevaría a algunas homogeneidades de que la comunicología latinoamericana -afirmó- carece. Apoyó, en cambio, otras alternativas, también aportadas por Marques de Melo, como la de "Vía Latinoamericana de Comunicación", argumentando además que quizá recién empecemos a configurar una Escuela Latinoamericana de Comunicación en torno a la propuesta del Dr. J. Martín Barbero, quien ha revolucionado los abordajes teórico-metodológicos de los procesos comunicacionales a partir de los medios y las mediaciones ${ }^{3}$. En el fondo del debate, quedaba también claro que en la aplicación académica, de investigación y en la definición propia del objeto de estudio, las teorías de la comunicación en Latinoamérica tienen asignado un papel central en la respuesta a esta discusión.

Indudablemente, como ya lo había diagnosticado años atrás el Dr. José Carlos Lozano (1996:13-16), la teoría de la comunicación en América Latina tiene asignado un papel clave en la respuesta a interrogantes como las anteriores, e incluso en la definición misma del objeto de estudio, pues la teoría es el punto de

1 Torrico Villanueva, Eric. (2000). "Eventos: Cochabamba Sede de la Más Grande Reunión Académica sobre Comunicación en Latinoamérica". Revista Pensamiento Comunicacional Latino-Americano. Universidad Metodista de San Paulo. Volumen 1, Número 2: Enero-Febrero-Marzo del 2000. pp. 6-8.

2 El Dr. Marques de Melo, además de ser uno de los investigadores más conspicuos en la región, ha constituido un grupo de trabajo especializado en el estudio sistemático y pormenorizado de la llamada Escuela Latinoamericana de Comunicación, poniendo en marcha para tal propósito la Revista Digital Pensamiento Comunicacional Latino-Americano, en el seno de la Universidad Metodista de San Paulo. En, Beltrán Salmón, Luis. "Investigación sobre Comunicación en Latinoamérica: Inicio, Trascendencia y Proyección”. Universidad Católica Boliviana y Plural Editores. La Paz, Bolivia. 2000.

3 En este sentido, además de la obra "De los Medios a las Mediaciones: Comunicación, Cultura y Hegemonía" (1987), se pueden consultar las siguientes publicaciones posteriores a está que Jesús Martín Barbero ha venido trabajando: "Comunicación, Campo Cultural y Proyecto Mediador" (1989); “Euforia Tecnológica y Malestar en la Teoría -en dialogo abierto con el prof. Mauro Wolf-" (1992); "Pensar en la Sociedad desde la Comunicación. Un Lugar Estratégico para el Debate a la Modernidad" (1993); "Comunicación: El Descentramiento de la Modernidad" (1996); "Globalización Comunicacional y Descentramiento Cultural" (1997); "Las Transformaciones del Mapa Cultural: Una Visión Desde América Latina" (1999); "El Futuro que Habita la Memoria" (2001) y, "Reconfiguraciones Comunicativas de lo Público" (2001/a). 
encuentro y desencuentro del análisis de los procesos de comunicación desde las diversas corrientes y enfoques disciplinares como la psicología, la sociología, la filosofía, la economía política, etc. Además, auguraba, que no se debe olvidar, la coexistencia teórica y metodológica que en las últimas ocho décadas han vivido varias disciplinas de las ciencias sociales que, por la cercanía reversible con el objeto/sujeto comunicacional, han influido de una manera decisiva en sus abordajes.

En este sentido, Martín Barbero (1993) menciona que el campo de estudios y, en particular, el desarrollo y la aplicación de las teorías de la comunicación en América Latina se formaron prácticamente durante el periodo de los sesenta y hasta mediados de los ochenta por el "efecto cruzado" de dos hegemonías teóricas: la del pensamiento instrumental de la investigación norteamericana y la del paradigma ideologista de la teoría social latinoamericana ${ }^{4}$.

A principios de la década de los noventa, sin embargo, las teorías de la comunicación en América latina han experimentado un cambio renovador, saludable y de necesaria superación. Este cambio, inicia a partir de cuatro aspectos y situaciones conexas fundamentales: por un lado, 1), de la superación de la decadente tendencia a adscribir los estudios de la comunicación a una disciplina e ir creando una conciencia creciente de su estatuto transdiciplinar, sin que esto signifique, lo que ya algunos investigadores como Nestor García Canclini (1989), Raúl Fuentes Navarro (1991), Martín Barbero (1999) y Vasallo de López (1999), recientemente han acotado sobre la disolución de sus objetos en los de las disciplinas sociales sino, por el contrario, la construcción de un diálogo articulado y de mediaciones que hacen y marcan precisamente su especificidad y reubican a la comunicación en el ámbito más amplio de las ciencias sociales. Por otro lado, 2), sobresale el rompimiento con lo que Lozano (1996) llama "los marcos sobreideologizados" de los enfoques teóricos del pasado y el divorcio alejado e inadecuado entre los estudiosos (profesores e investigadores) de la comunicación y de los estudiantes y profesionales de esta; 3), con el advenimiento y convergencia de tecnologías informáticas, de telecomunicaciones y audiovisuales, se revolucionaron las formas de producción, difusión y recepción de la información que han

4 En la revisión del periodo y los efectos de las hegemonías, Martín Barbero se ve obligado a plantear una recomposición del campo y de las consecuencias de las apropiaciones teóricas que traspase los enfoques y las fronteras de los campos disciplinares, utilizando este análisis para la construcción del campo transdiciplinar de la comunicación. Para Barbero, las bases que sustentaron la teoría de la comunicación y que explicó el fenómeno (comunicacional) desde los cuarenta hasta mediados de los ochenta en América Latina son: la corriente de la psicología conductista, la sociología funcionalista (positivista, empirista, especulativa y escolástica) y la "amalgama esquizoide" de la semiología estructuralista y el marxismo clásico de la Escuela de Frankfurt. En, J. Martín Barbero. 1992. "Pensar en la Sociedad desde la Comunicación. Un Lugar Estratégico para el Debate a la Modernidad”. En Revista Diálogos de la Comunicación № 32. FELAFACS. Lima, Perú. 
hecho posible lo que Martín Barbero (2001) llaman la "alteración de las relaciones tradicionales de intercambio entre emisores y receptores y usuarios mismos" hasta el punto de permitir otras modalidades de interrelación mediatizada pero interactiva, dialógica, en tiempo real e incluso, personalizadas, en un espacio globalizado, sin fronteras, sin limitaciones, que nos permite movernos entre los límites de lo global a lo local de manera simultánea. Finalmente, 4), lo anterior repercutió fuertemente en la recuperación de la producción de la enseñanza y la investigación de la comunicación en América Latina y su intercambio con el plano internacional del cuál se había estado, según Marques de Melo (1999), muy distanciado e incluso, desfasado.

Sin embargo, lo anterior no debe confundirnos. La instrumentación de las teorías de la comunicación en América Latina se encuentra hoy en día en una situación de crisis en los paradigmas teóricos y metodológicos de las ciencias de la comunicación sobre todo porque, por un lado, su visión instrumental y pragmática del fenómeno ha impedido ver con multiplicidad y riqueza el proceso comunicativo y, por otro, la globalización y el neoliberalimo que nos acompañan desde hace casi dos décadas en la región, no han resultado ser un proceso simple sino complejo y lleno de paradojas, que destaca las contradicciones sociales y sitúa en tela de juicio todas las verdades y certidumbres sobre las cuáles el hombre moderno se había apoyado para entender y explicar su mundo.

En este sentido, un grupo de investigadores de comunicación del Departamento de Ciencias de la Comunicación de la Universidad de Sonora, México, nos hemos propuesto abordar algunas interpretaciones de teóricos y estudiosos actuales de la comunicación con el objeto de conocer y analizar acerca de las inercias e iniciativas predominantes en la instrumentación de las teorías de la comunicación en Latinoamérica en los últimos quince años y, consecuentemente, revisar en prospectiva, la emergencia de los principales enfoques teóricos-metodológicos que explicarán en los años venideros los cambios que introducen las tecnologías de información en los multivariados procesos de comunicación en nuestra región.

Por motivos de espacio, en el presente documento se presenta exclusivamente una primera aproximación de carácter descriptivo-analítica de la situación actual de las teorías de la comunicación en Latinoamérica a partir del estado actual que guardan las teorías y la investigación de la comunicación en Latinoamérica a partir de los elementos de análisis del modelo de comunicación mismo: 1). Producción y distribución de mensajes; 2). Contenido del mensaje y, 3). Recepción del mensaje;

Por último, quisiéramos reparar en la tilde que marca, hasta cierto punto, la guía del desarrollo, presentación y manejo de los contenidos sucesivos. Por un lado, el trabajo se desarrolla a partir de la revisión de la literatura actual y especializada que sobre el tema existe en algunos países de Latinoamérica, principalmente aquellos documentos que con carácter de productos de investigación 
sobre la temática se han publicado en los últimos quince años; aquí sobresalen los trabajos que con gran riqueza y sentido crítico se han producido en Brasil, Perú, Bolivia, Chile, Argentina, Venezuela y México, entre otros ${ }^{5}$. Además, lo publicado, con igual carácter, en España e Italia.

Por otro lado, en la guía de desarrollo de contenidos del presente ensayo tratamos de reflejar una mística productiva que marcadamente encontramos en diversos documentos analizados: el sentido que ha marcado, desde principios de la última década, la reforma curricular en las escuelas de comunicación en América Latina y, consecuentemente, en la definición del objeto de estudio de la comunicación ${ }^{6}$.

\section{Teorías de la Comunicación en América Latina. Situación Actual}

\subsection{Contextualización.}

Si la teoría debe ser concebida en función de la investigación que se está realizando, esto es, dirigida a la experiencia de lo real en el cuál ella se confronta con los hechos que esta misma suscitó con sus hipótesis, la situación de las teorías de la comunicación en América Latina a diferencia de las tres grandes "orientaciones conceptuales" (la orientación europea clásica histórica y filosófica, la orientación positiva norteamericana y la orientación europea moderna-semiótica y estructuralista-) que el Dr. Luis R. Beltrán presentó en su celebre recuento sobre

5 Por lo que respecta a los investigadores más notables, podemos citar, entre otros, a los mexicanos Esteinou Madrid, Fernández Christlieb, Fuentes Navarro, García Canclini, Gómez Mont, Galindo Cáceres, Jorge A. González, Orozco Gómez, Sánchez Ruiz, Lozano Rendón y Trejo Delarbre; los brasileños Caparelli, Díaz Bordenave, Marques de Melo, Vasallo y Lins da Silva; los colombianos Daza Hernández, Martín Barbero y Muñoz; los argentinos Ford, Getino, Landi, Mata, Prieto Castillo, Rivera y Schmucler; los chilenos Brunner y Fuenzalida; los peruanos Alfaro, Gargurevich, Protzel, Roncagliolo y Tello Charún; los venezolanos Aguirre, Bisbal, Díaz Rangel, Mayobre y Pasquali; el boliviano Luis R. Beltrán, y el uruguayo Kaplún. Cada uno de estos destacados investigadores, aunque desde perspectivas e intereses teóricos distintos, han contribuido particularmente al afianzamiento de los estudios interdisciplinares de este fenómeno, sobre todo mediante la publicación periódica de libros, informes, ponencias y revistas diversas.

6 Esto se debe en parte al debate que sobre diseño curricular han aportado Fuentes Navarro, Martín Barbero, Daniel Prieto, Marques de Melo y Pablo Casares, principalmente; diseño curricular y las teorías de la comunicación han marcado la bifurcación y jerarquización regulada por el mismo marco ideológico-valoral: la de una caracterización del ejercicio profesional deseable y un conjunto sistematizado de postulados teóricos, confluencia que define, a su vez, el objeto de la carrera. Al respecto ver, Fuentes Navarro, R. 1990. "El Diseño Curricular en la Formación Universitaria de Comunicadores Sociales para América Latina". En Revista Dia-logos de la Comunicación No 17. FELAFACS. Lima, Perú; José Marques de Melo. 1991. "Desafios Actuales de la Enseñanza de la Comunicación. Reflexiones en Torno a la Experiencia Brasileña". En Revista Dia-logos de la Comunicación No 19. FELAFACS. Lima, Perú. Jesús Martín Barbero. 1991. "Crisis en los Estudios de Comunicación y Sentido de una Reforma Curricular". En Rev. Dia-logos de la Com. No 19. FELAFACS. Lima, Perú. Jesús Martín Barbero. 1993. “Teoría / Investigación / Producción en la Enseñanza de la Comunicación”. En Rev. Dia-logos de la Com. № 32. FELAFACS. Lima, Perú. Moragas Spa, M. 2000. "Las Facultades de Comunicación en el Umbral de la Era de Internet". Rev. Latinoamericana de Comunicación Chasqui. N ${ }^{\circ}$ 72. Diciembre del 2000. 
[La Investigación de la Comunicación en América Latina] hace ya veintiséis años ${ }^{7}$, actualmente esta situación se encuentra en una polarización de fundamentos epistemológicos, teóricos y conceptuales (más no metodológicos) de aproximación a la realidad que se concentra, según Fuentes (1999: 53), en dos paradigmas: Aquella relacionada con el enfoque positivista, funcionalista y empirista en su abordaje científico de la construcción de la realidad social y, aquella que, por el contrario, parte de una visión crítica y dialéctica para entender los fenómenos sociales y comunicacionales.

En América Latina, como ya han señalado histórica y sistemáticamente Beltrán (1974, 1994), Sánchez Ruiz (1992), Lozano (1996) y Fuentes (1999), el enfoque teórico positivista se desarrollo principalmente en los Estados Unidos y, junto con sus principales teóricos (Schramm, Berlo, Lazarsfeld, Bertalanffy, Parsons, Katz, McQuail, McCombs, y Luhmann), prácticamente los modelos conceptuales de este han y siguen estando, incluso sin mediaciones ni adaptaciones, predominando.

En este enfoque, el científico social no constituye un agente de cambio. Es un observador objetivo que desde afuera analiza causas y leyes que rigen los fenómenos y procesos comunicacionales utilizando para ello estrategias metodológicas basadas en el método empírico y sistemático para tratar de separar el conocimiento científico de los sentimientos subjetivos y filosóficos. Por lo general, utilizan la aplicación de técnicas cuantitativas (fundamentalmente de experimento, encuesta y análisis de contenido).

Por vías diferentes, el enfoque positivista tiene diversas manifestaciones conceptuales y teóricas sobre la comunicación (análisis funcional, influencia personal, usos y gratificaciones, establecimiento de la agenda -agenda setting-, análisis de cultivo, sociología de la producción de mensajes), aún cuando los positivistas, según Lozano (1996: 25), han reconsiderado la influencia de los medios y perciben algunas de sus insuficiencias (por ejemplo, los enfoques como agenda setting, análisis de cultivo y la sociología de la producción de mensajes).

El enfoque teórico crítico cuyo origen proviene de Europa, por el contrario, analiza, previo análisis de los procesos comunicacionales, las características de las condiciones económicas, sociales, de educación, de poder y hegemonía en los

7 En la investigación que presentó en septiembre de 1974, con base sobre todo en la documentación compilada por la CIESPAL, Luis Ramiro Beltrán enumeraba las principales áreas de concentración temática de investigación, subrayando, las tendencias en cuanto a tópicos investigados y a resultados obtenidos en los últimos quince años. En sus conclusiones presagió que en Latinoamérica se consolidaría la promoción de investigadores en dos tipos de contexto: los críticos, en un contexto de cambio sociocultural acelerado y, los semiólogos y estructuralistas, en un contexto donde la influencia científica europea es firme. En, Luis Ramiro Beltrán. Communication Research in Latin America: The Blind Folded Inquirí?. ICC. IAMCR. Leipzig, September 17th. 1974. p.23. Citado en, Raúl Fuentes N. 1999. "La Investigación de la Comunicación en América Latina: Condiciones y Perspectivas para el Siglo XXI". Rev. Diálogos de la Com. N ${ }^{\circ}$ 56. FELAFACS. Lima, Perú. 
diferentes sistemas contemporáneos para cuestionar los roles que juega la comunicación en la preservación del sistema social y el papel de los mensajes en la difusión de la ideología dominante. En este enfoque, el científico social se concibe, tal y como se deja ver en los discursos de Martín Barbero (1996: 61.), como un agente de cambio, comprometido ética y socialmente.

Los teóricos críticos se caracterizan por situar el estudio de los procesos comunicacionales dentro del más amplio contexto social y analizarlos no en forma aislada sino como organizaciones dedicadas a la producción y distribución de significados sociales en sus relaciones integrales dentro de la sociedad, la cultura, la modernidad y la globalidad, mediante la estrategia metodológica histórica, crítica y dialéctica e implementando, por lo general, técnicas cualitativas (entrevista a profundidad, historia oral, observación participante y análisis semióticos y estructuralistas).

Al enfoque crítico se le identifica, al menos, con cuatro corrientes: La escuela crítica de Frankfurt, la economía política, el imperialismo cultural y los estudios culturales; sobresalen de éstas algunos teóricos como los neomarxistas de la Escuela de frankfurt (Adorno, Horkheimer, Benjamín, Marcuse, Althusser, Murdock y, principalmente, Habermas); los de la escuela europea estructuralista y semiótica (Gramsci, Foucault, Chomsky, Eco y Wolf) y, más recientemente, la escuela de los estudios culturales donde sobresalen Williams, Fiske, Morley, Jensen y Stuart Hall que, junto con otros teóricos actuales como Green, Giddens, Douglas \& Ischerwood, J. B. Thompson, Morley y Certeau, han inspirado fuertemente a la corriente crítica culturalista Latinoamericana.

Esta última, también llamada Escuela Culturalista Latinoamericana (Beltrán Salmón, 2000:14), ha hecho aportaciones teóricas, conceptuales y de investigación empírica en el plano internacional. Entre sus teóricos más representativos figuran Martín Barbero, N. García Canclini, Guillermo Orozco, V. Fuenzalida y J. A. González ${ }^{8}$.

Sin embargo, es importante reconocer, que en la actualidad las "etiquetas" de los enfoques positivistas y críticos resultan poco útiles para denotar y caracterizar los postulados teóricos en ambas corrientes; principalmente, porque las teorías de comunicación positivistas que actualmente tienen vigencia en Latinoamérica (desde el punto de vista de investigación y docencia), es decir, los

8 En el caso particular del Dr. Jorge A. González, de la Universidad de Colima, México, en realidad sus aportaciones no podrían ubicarse, como él mismo lo ha dicho, en el plano teórico del estudio de la comunicación sino en el plano metodológico de los estudios [frentes] culturales e identidades complejas.

"...Mi trabajo teórico no creo que hasta la fecha haya impactado en los estudios de la comunicación, porque en realidad poco me he dedicado a la comunicación... Creo que lo más significativo serían algunas aportaciones y desarrollo de técnicas, métodos y metodologías...". En, Temer, Carolina. 2001. "Forjando as Bases Teóricas Pensamento Comunicacional Latino-Americano". Revista Pensamento Comunicacional Latino-Americano. Vol. 2 Núm. 6 Abril-Junio, 2001. p.2. 
enfoques de análisis de cultivo, el establecimiento de la agenda y de la sociología de la producción de mensajes, consideran la influencia de los mensajes y perciben algunas de sus claras insuficiencias, tal y como adelante analizaremos.

De igual manera, dentro de las teorías de comunicación crítica que actualmente tienen mayor vigencia en América Latina, los estudios culturales, se han distanciado del criticismo pesimista y han roto en gran medida con la concepción de la recepción pasiva y manipulable. Para abordar la situación actual de las teorías de comunicación en Latinoamérica proponemos, tal y como ya lo adelantábamos, una descripción analítica a partir de los elementos básicos del modelo de comunicación mismo: 1). A partir de los procesos de producción y distribución de los mensajes; 2). De los contenidos del mensaje; 3). De la recepción del mensaje y, finalmente, 4) realizar una descripción de cuál es la relación que guardan hoy en día la teoría y el método de estudio en el abordaje de los procesos comunicacionales en América Latina.

\section{Cuadro $\mathrm{N}^{0}$. I}

Enfoques teóricos dentro del Modelo de Comunicación Masiva

E $\mathrm{m}$ i s o r

Sociología de la Producción del Mensaje

Economía Política

Agenda

Imperialismo Cultural
M e n s a j e

Análisis de Cultivo

Establecimiento de Agenda

Imperialismo Cultural

Estudios Culturales
$R$ e c e p t o r

Análisis de Cultivo

Establecimiento de la

Usos y Gratificaciones

Estudios Culturales

Fuente: Lozano Rendón, J. (1996: 27).

2.2. Teorías de la Comunicación en América Latina desde los Procesos de la Producción y Distribución del Mensaje.

Para iniciar con un entendimiento completo de los medios de comunicación y su impacto social requiere analizar a fondo los procesos de producción y distribución de los mensajes, pues el contenido y el impacto en la audiencia dependen de lo que haya ocurrido en las diferentes etapas y procedimientos de su manufactura. Dentro del enfoque positivista de las teorías de la comunicación y particularmente con respecto al estudio sobre los emisores, se encuentra el enfoque llamado sociología de la producción de mensajes. De acuerdo con Lozano (1996: 57-58.), el estudio de los procesos de elaboración y selección de noticias evoluciona a un enfoque más completo y amplio, al que le podemos denominar sociología de la producción de mensajes.

Este enfoque tiene como finalidad central el estudiar las diversas condicionantes que inciden en la producción de los mensajes en los medios y que determinan que ciertos contenidos se difundan y otros no. La pregunta que se formula 
esta perspectiva teórica es ¿Qué factores, desde dentro y desde afuera de las organizaciones de los medios, afectan el contenido de los medios?.

El nombre con el que se le identifica a este enfoque en los Estados Unidos es media sociology. En la versión europea, el Profesor bolones Dr. Mauro Wolf, lo denominó el enfoque del Newsmaking o producción de noticias. Para Wolf (1987: 203), el estudio de los emisores se desarrolla desde algunos conceptos simples hasta articulaciones más complejas y entre variantes que no corresponden necesariamente a la lógica productiva interna de los medios.

Entre estas variables y factores, los investigadores de esta tendencia como Shoemaker \& Reese (citados en Lozano, 1996: 58.), analizan las actitudes personales y las orientaciones formativas e ideológicas de los comunicadores -incluyendo las variables estructurales del sujeto-, los valores profesionales, las políticas corporativas de los medios, la propiedad y el control de los mismos, las condiciones que se derivan del sistema económico y las influencias ideológicas del sistema social.

Según Wolf (1987:203-4), dos son las corrientes principales de este enfoque: La sociología de las profesiones, que estudia al emisor desde la óptica de sus características sociológicas y culturales y, por otro lado, la corriente de estudio que analiza la lógica de los procesos de producción de la comunicación de masas y el tipo de organización en el que tiene lugar dicha construcción del mensaje.

En América Latina, aún cuando son pocos los estudios empíricos y sistemáticos, sobresalen los trabajos que principalmente se han realizado en la segunda corriente de este enfoque (procesos de producción y tipo de organización y decisiones) como los de González Molina (1987), Aguirre (1992), Lozano (2001, 1995), García Gutiérrez (2000) y Morera (2001).

Muy cercano al enfoque de la sociología de la producción de mensajes, pero con énfasis en los condicionamientos más amplios, característicos del enfoque crítico, es el de la economía política crítica. Esta perspectiva, de gran tradición en este enfoque, presenta actualmente cambios en los postulados originales de Marx y Engels (basados en que la clase dominante que posee y controla los medios de producción material, posee a su vez el control ideológico de las demás clases) según los dos representantes más sobresalientes, los británicos Murdock \& Golding.

Las diferencias principales de los postulados originales se concentran en cuatro aspectos: Por tener una visión holística histórica (interacción entre la organización económica, la vida política, social y cultural), por la preocupación de balancear la connotación del estudio entre la iniciativa privada y la intervención pública de gobierno y, lo más notable, que va más haya de las cuestiones técnicas para abordar cuestiones morales básicas como la justicia y el bienestar común.

De acuerdo con Murdock y Golding (citados en Vela, 2000:6), pese a la importancia que reviste el concepto de «determinación económica», en el marco 
concreto de los estudios culturales, dicho concepto necesita una redefinición, una nueva reinterpretación que permita a la disciplina desembarazarse del lastre del reduccionismo economicista $\mathrm{y}$, sobre todo, que haga posible volver a atar las amarras de los estudios culturales a los muelles firmes y rigurosos de la economía política. Sólo redefiniendo el concepto de determinación en un sentido más abierto, laxo y complejo, que nos hable de marcos o límites genéricos y no de correspondencias ineludibles y necesarias o de efectos plenamente previsibles, se podrá no sólo recuperar las imprescindibles aportaciones con las que la economía política contribuye a los análisis de la cultura (aportaciones de las que, por otra parte, los estudios culturales decidieron prescindir en su abandono de la sociología marxista), sino también la potencialidad explicativa de los análisis sociológicos marxistas 9 .

Para Murdock \& Golding, la economía política crítica tiene tres áreas de análisis prioritarias: 1). La producción de bienes culturales, en el sentido en cómo las condiciones de producción del mensaje impactan en el rango de opciones de recepción del consumo; 2). La producción y consumo de los mensajes de los medios, donde relacionan la realidad material de su producción y su consumo y, 3). El consumo cultural, para ilustrar la relación entre la desigualdad material y la cultural.

En América Latina, abundan actualmente productos de investigación del enfoque de la economía política crítica. Sobresalen los trabajos del Dr. Javier Esteinou Madrid, del Departamento de Educación y Comunicación de la Universidad Autónoma Metropolitana, que aborda, desde una visión crítica, el análisis de los medios de comunicación masiva a nivel macro y con una visión holística desde la globalidad y la cultura (1985, 1991, 1992, 1994, 1995, 2000, 2000/a, 2000/b). Otros representantes que han venido trabajando sobre la línea de este enfoque de manera sistemática son los profesores Trejo Delarbe $(1985,1999)$ y Fernández Christlieb $(1982,1987)$ y Beltrán y Fox $(1981,1989)$.

En el enfoque crítico, una corriente que se ha preocupado históricamente por los constantes desequilibrios y desigualdades en los flujos de los medios y los

9 El británico Raymond Williams, uno de los teóricos fundadores de los estudios culturales, expresaba una idea similar en cuanto al principio de determinación al señalar que ésta no podía ser nunca (como pretende la teoría marxista ortodoxa) un conjunto de causas que establece un control absoluto con resultados totalmente previsibles. Por el contrario, como ya lo ha señalado Vela Montero, Williams entendía la determinación de base económica "como los límites definidos entre los cuales las prácticas sociales superestructurales se desarrollan influidas en gran medida por la base, pero sin llegar en ningún momento a estar totalmente controladas por los elementos de la estructura económica. Las prácticas sociales supraestructurales pueden, de este modo, estar sujetas a una serie de límites (económicos) y sometidas a un conjunto de presiones, pero nunca estarán totalmente controladas ni llegan a ser absolutamente previsibles..." En, José A. Vela Montero (2000). "Los Estudios de la Audiencia: Una Visión Crítica desde la Economía Política". Revista Ámbitos No 5, Sevilla, 2 semestre de 2000. 
mensajes entre países industrializados y los tercermundistas es el enfoque del imperialismo cultural.

Los teóricos de esta corriente que tradicionalmente han sobresalido en Latinoamérica son Beltrán (1974, 1978, 2000), J. Esteinou (1982, 1991, 1992) Sánchez Ruiz (1992, 1997) y Mattelart (1970, 1972, 1975, 1994, 1997, 1998), los cuáles, por lo general, ubican el estudio de la comunicación masiva dentro del contexto de las relaciones económicas y políticas internacionales de los países industrializados y los países de América Latina (en vías de desarrollo), para analizar los flujos de comunicación uniformes y de dependencia como los mecanismos de influencia cultural que se presentan.

Según Mattelart (1997: 12-17.), los estudios de este enfoque surgen fuertemente en nuestra región a partir de los setentas pero no es sino hasta principios de la década de los ochenta, en el marco de la entrada y establecimiento del estilo de vida global, que los estudios en nuestra región aumentan en términos sustanciales impulsados por los grandes grupos de comunicación que contribuyen ampliamente a la construcción del tecnoglobalismo y a la implantación de la visión experimental de la cultura sobre la "convergencia cultural" y el fin de la heterogeneidad cultural Latinoamericana.

Algo que ha caracterizado en la década de los noventas a la corriente del imperialismo cultural son las numerosas tendencias que subyacen en la estructura misma de la teoría de la comunicación Latinoamericana. De acuerdo con la Dra. María Martín Díez (2000: 39-42.), de la Universidad Europea de Madrid, su investigación al respecto le ha llevado a descubrir que, a pesar de que existe en América Latina una gran riqueza de estudios, prevalecen actualmente una amplia diversidad de tendencias en este enfoque, entre las cuáles se pueden destacar las siguientes relaciones paralelas y opuestas en el abordaje de los medios: 1). Regionalización versus globalización; 2). Poder autónomo versus poder dependiente; 3). Proteccionismo versus librecambismo; 4). Estatismo versus privatización; 5). Civilización occidental versus otras civilizaciones; 6). Culturas propias versus cultura norteamericana; 7). Exposición ideológica directa versus método de entretenimiento.

Sin embargo, lo anterior a también a provocado una gran dispersión teóricametodológica del estudio y ha propiciado visiones incompletas, inconsistentes y a menudo poco confiables de los procesos internacionales de comunicación por lo que se puede advertir, según Lozano (1997: 3-4.), que aunque casi todos los teóricos latinos parten de una perspectiva crítica, hoy en día algunos ya lo hacen desde el enfoque de la economía política, otros del imperialismo cultural y, otros más, desde diversas posiciones culturalistas $^{10}$. Incluso, afirma, algunos parecen

10 En el caso de México, por ejemplo, Lozano ejemplifica que no existen visiones integradas y consistentes en la totalidad de los procesos sino sólo de algunas partes: Por ejemplo, los trabajos teóricos de Javier 
mezclar indiscriminadamente aspectos de unas y otras, sin intento alguno de reconciliar las tensiones entre ellos, produciendo una mayor confusión conceptual.

En análisis a prospectiva, Lozano (1997: 7.), presenta cuatro aspectos que tendrán que corregirse en un futuro mediato: 1). Clarificar abordajes teóricos; 2). Delimitar los abordajes desde el campo de la comunicación; 3). Darle igual peso analítico a todas las partes del proceso y, 4). Realizar mayor cantidad de investigaciones empíricas que permitan la comprobación, refutación o reformulamiento de las teorías existentes.

2.3. Teorías de la Comunicación en América Latina desde el Contenido del Mensaje

La mayoría de los enfoques teóricos sobre la comunicación de masas toman en cuenta, de una manera u otra, el contenido de los mensajes de los medios pues estos proporcionan indicios ya sea desde los procesos de producción y sus condicionantes ó, como adelante veremos, desde los posibles impactos o usos que se pueden suscitar en los procesos de recepción.

Según Lozano (1996: 114-116.), el estudio científico del contenido de los medios tiene una larga tradición tanto en la perspectiva positivista como en la crítica pues, en todos los diversos enfoques conceptuales, los mensajes constituyen o incorporan rasgos y evidencias de los procesos de producción (sociología de la producción de mensajes, economía política e imperialismo cultural) y, a su vez, proporcionan también inferencias para determinar su posible impacto o apropiación por parte de las audiencias (análisis de cultivo, establecimiento de la agenda, estudios culturales).

La sociología de producción de mensajes, ha utilizado el análisis de los mensajes para corroborar sus hipótesis sobre el efecto de los diferentes condicionamientos que provoca su producción en el contenido final de los medios. En este sentido, las investigaciones se han centrado en dos aspectos: 1). En detectar si los contenidos de las noticias se recopilan mediante los canales rutinarios o bien, si provienen de la creatividad y las pesquisas de sus reporteros y, 2). En analizar si los contenidos del mensaje provienen efectivamente de las fuentes informativas que aparecen citadas las noticias. En América Latina, con excepción hecha de los trabajos de Lozano (1994), Esteinou (2000/a, 2000/b) y Gutiérrez Renteria (2001), son prácticamente inexistentes los desarrollos teóricos al respecto.

En lo que respecta a los teóricos del imperialismo cultural y la economía política en Latinoamérica, estos han estudiado el contenido de los mensajes

Esteinoú en la línea del imperialismo cultural; de Enrique Sánchez Ruiz en la línea de economía política y de Jorge A. González y Guillermo Orozco en la veta culturalista. En, Lozano, José Carlos. 1997. "La Investigación sobre la Comunicación Internacional en México". Revista Razón y Palabra. № 7 . Año 2. Junio-agosto. 1997. p. 4-5. 
extranjeros para detectar la presencia de valores ideológicos y culturales ajenos a la idiosincrasia y necesidades de los países Latinoamericanos. Como anteriormente se mencionó, los autores representativos en la región son Mattelart, Beltrán y Esteinou.

Por otro lado, entre las perspectivas teóricas positivistas que estudian los contenidos del mensaje y los efectos a largo plazo en las cogniciones y en la formación de las actitudes en los individuos, se encuentran el análisis de cultivo y el establecimiento de la agenda. El análisis de cultivo como perspectiva teórica ha contribuido a la reconsideración de la influencia de los medios (en especial la televisión) como agentes de socialización y cambio mediante la exposición al patrón total de programación mediática más que a géneros o programas específicos.

De acuerdo con las investigaciones de Gerbner \& Gross (citados por Lozano, 1996: 135-137), las implicaciones de la exposición acumulada al sistema general de mensajes, imágenes y valores que transmiten y repiten los medios, no deben de ser medidos sólo en términos de cambios inmediatos en el comportamiento, sino también, por el grado en que cultivan ciertas perspectivas de la vida, pues a lo largo de los meses y los años, los televidentes van absorbiendo, poco a poco, cogniciones que, a fuerza de repetirse, se transforman lentamente en actitudes y, muy a largo plazo, propician ciertas conductas.

Para el Prof. Wolf (1997: 7), este tipo de investigaciones, que le parecen particularmente relevantes, se centran en describir la forma en que los medios actúan sobre la realidad subjetiva: de los efectos puntuales se pasan a la influencia acumulativa, la que no se identifica ni atribuye a ningún hecho comunicativo específico ni a ningún mensaje particular, sino a la presencia misma de los medios, a la totalidad del contenido de sus discursos. Es lo que Wolf llama "una suerte de ecología de la comunicación": La acumulación constante de mensajes en sucesión y frecuencia "natural" y en su forma del discurso, que todo le da sentido y significado a los contenidos ${ }^{11}$.

En forma paralela al enfoque del análisis de cultivo, se ha desarrollado la perspectiva del estableciemiento de la agenda (agenda setting). Apoyada en los mismos desarrollos teóricos que visualizan la influencia de los medios a largo

11 Mauro Wolf, Profesor e Investigador italiano del Departamento de Comunicación de la Universidad de Bolonia, fue, hasta su muerte, en el verano de 1996, uno de los más importantes teóricos de la comunicación. En franca manifestación de interés por los recientes acercamientos entre la sociología fenomenológica, la investigación semiótica y la comunication research, el Profesor Wolf llegó a la conclusión que el factor más significativo de este acercamiento es el esfuerzo de comprensión de dichas perspectivas teóricas por conocer los efectos y las influencias puntuales que de manera diacrónica o de largo plazo generan los contenidos del mensaje y los contenidos del discurso de los medios. En, Wolf, Mauro. 1997. "Los Emisores de Noticias en la Investigación sobre Comunicación”. Zer, Revista de Estudios de Comunicación. Universidad del País Vasco. N 3. Noviembre de 1997. 
plazo y en las cogniciones (a cerca de que pensamos) y las opiniones y sentimientos (lo que pensamos), este enfoque se centra en el estudio del impacto de la prensa y la información política en el público.

Según Wolf (1990: 1), el camino histórico que ha seguido el modelo de la agenda setting es, en primer término, el establecimiento y formulación de la hipótesis clásica de Shaw, que, aunque tiene antecedentes en Lippmann \& Newmann, esta inicia en 1972 y concluye a fines de los setentas; posteriormente, el desarrollo de las investigaciones empíricas de Mccombs y Shaw, las cuáles se desarrollan hasta mediados de los ochentas, donde se distinguen las primeras condiciones contingentes en los grupos de receptores y, finalmente, la aplicación de la agenda-building, como desarrollo de la agenda setting, la cuál es una tendencia de integración de territorios con una definición articulada del concepto de agenda pública.

La formulación clásica de la hipótesis que plantean los teóricos de la agenda setting como Shaw (citado en Wolf, 1987: 163-166), parte de que los medios, al describir y precisar la realidad externa, presentan al público una lista o agenda de todo aquel en torno que se puede opinar y discutir por los lectores. Shaw, al poner el acento en la creciente dependencia cognoscitiva de los medios, la hipótesis de la agenda postula un impacto directo, aunque no inmediato, sobre los destinatarios, que se configura a partir de dos niveles: Por un lado, el orden del día de los temas en la agenda de los medios y, por otro, la jerarquía de importancia y prioridad con la que dichos temas son dispuestos en la agenda.

De acuerdo con las investigaciones empíricas de McCombs \& Shaw (citadas en Lozano, 1996: 149-155), las cuáles proporcionaron las primeras evidencias empíricas de este enfoque, sugieren que los medios al proponer contenidos temáticos sí generan importantes efectos en los receptores. Según McCombs, las conclusiones de la trayectoria de los estudios de la agenda setting pueden sintetizarse en: Primero, que los efectos de la agenda de los medios no son automáticos ni mecánicos; segundo, que el énfasis constante en ciertos temas por parte de los medios tiende a propiciar preocupación pública sobre ellos; tercero, que el efecto de la agenda se manifiesta con mayor fuerza en términos de conocimiento sobre el tema que de la opinión sobre el mismo; y, cuarto, que la mayor cantidad de información sobre el tema propuesto por la agenda no es garantía de una mejor opinión sobre él sino dependerá de las creencias y valores preexistentes con que cada persona enfrente los mensajes comunicacionales.

Una de las principales limitantes para la aplicación del análisis de cultivo como de la perspectiva del establecimiento de la agenda en América Latina es la muy escasa investigación empírica existente fuera de los Estados Unidos, aún cuando, según Lozano (1996: 158.), ambos enfoques tienen un gran potencial de aplicación y desarrollo en nuestra región debido a dos causas: 1). Por la gran cantidad de programación televisiva importada de Estados Unidos sumado a las 
constantes imitaciones locales de los mensajes y programas de ese país, y, 2). Al papel cada vez más importante que juegan los medios informativos en los procesos electorales y políticos de los países latinoamericanos.

2.4. Teorías de la Comunicación en América Latina desde los Procesos de Recepción y Apropiación del Mensaje

Gran parte del desarrollo de las teorías de la comunicación y del estudio científico de la comunicación de masas a nivel mundial y, particularmente, en América Latina, ha girado alrededor de las audiencias y del impacto de los mensajes en ellas. Esto se debe, en el fondo del debate actual, a que las tecnologías mediáticas no son neutras y sí inciden y constituyen, hoy más que nunca, los enclaves de condensación e interacción de las mediaciones sociales, conflictos simbólicos e intereses económicos y políticos. O bien, como lo sugiere Martín Barbero (2001: 81.), porque los mensajes y sus impactos, generan nuevas y variadas formas de entrelazamiento de lo social y lo político, de la formación de la opinión pública y del ejercicio de nuevas formas de ciudadanía.

A más de sesenta años del nacimiento y desarrollo de los primeros estudios (legítimos o no) de los efectos de los medios, los cuáles tuvieron como bases científicas a la psicología social y a la sociología funcionalista norteamericana -con Lasswell (1927, 1935, 1949), Lazarsfeld (1941, 1948), Schramm (1949, 1954) y Merton $(1946,1957)$ en su dirección-, la vieja concepción, planteada por la teoría de la aguja hipodérmica, de que las audiencias de los medios son pasivas y manipulables, fue sustituida por la visión de los receptores como sujetos activos: David Berlo, en 1970 (citado en Beltrán, 1994: 105.), fue el primero en plantearse, al hablar de los nuevos deberes de los comunicólogos, la necesidad de concentrarse en "... las maneras en que la gente usa los mensajes y no, como lo hicimos, en el pasado, en [...] las maneras en que los mensajes pueden usar a la gente"12.

Una de las primeras teorías de comunicación posteriores al enfoque positivista y funcional, que se encargan de indagar los nuevos comportamientos de la audiencia activa es el enfoque de usos y gratificaciones. Esta perspectiva de investigación vigente hoy en día, concluye que las audiencias experimentan una serie de necesidades de carácter informativo y de orientación y usan a los medios, entre otras alternativas funcionales, para satisfacerlas.

12 De hecho, Luis Ramiro Beltrán, trae a colación la cita del Dr. Berlo tras una sugerente y rica indagación de los avances de investigación que hasta los setenta se podían encontrar en América Latina: Por un lado, “...aparentemente han prevalecido una orientación metodológica marxista en la orientación de la investigación [en países como Chile, Perú y Cuba] ... y por otro, [en países como Argentina y Brasil] la semiología, la ciencia de los signos y los símbolos, ha brindado inspiración junto con los métodos de la semántica estructural aliada con la sociología del conocimiento...". Beltrán, Luis R. "Premisas, Objetos y Métodos Foráneos en la Investigación sobre comunicación en América Latina”. En, De Moragas Spa, M. Sociología de la Comunicación de Masas. Escuelas y Autores. Ed. Gili. Barcelona. 1994. 
Así, cada mensaje y cada contenido de los medios, puede cumplir diferentes funciones dependiendo del uso que cada persona le diera, incluyendo no solamente la selección de gratificación de su necesidad, sino que también los evitan selectivamente como lo sugiere De Fleur y Ball Rokeach (1991: 254.), al analizar los estudios de los roles de la teoría de usos y gratificaciones que expuso Blumer \& Katz a fines de 1979.

En Latinoamérica han sido muy pocas las investigaciones que hasta hoy se han realizado en este enfoque. Las dos razones principales han sido porque los teóricos latinoamericanos asumen que en lo general los mensajes siguen favoreciendo principalmente los intereses de la clase hegemónica y proponen consecuentemente significados preferentes o dominantes; por otro lado, porque se sigue rechazando el ya viejo modelo del psicologismo de Lasswell y Lazarsfeld de estudiar al receptor en forma individual, por fuera de su contexto sociocultural. Entre los pocos trabajos que encontramos como representativos de este enfoque están los estudios recientes de los investigadores chilenos Gaete Martínez (2000) y Zepeda (2000).

Si en el enfoque de usos y gratificaciones América Latina no ha sobresalido, en la vertiente de los estudios culturales de los procesos de recepción y apropiación del mensaje, los teóricos de nuestra región han hecho importantes aportaciones en el ámbito mundial ${ }^{13}$.

Inspirados en primera instancia por las aportaciones hechas a fines de los setentas por los estudios críticos culturales (individuos y su pertenencia a subculturas), sobre la polisemia del mensaje de los medios (la existencia de significados hegemónicos y alternativos en un mismo contenido), que aplicó como modelo teórico Stuart Hall y como investigación empírica David Morley (citados en Lozano, 1996: 192-194), el enfoque de los estudios culturales en Latinoamérica a partir de implementar una fuerte vertiente de desarrollo de elaboraciones teóricas y de aproximaciones metodológicas diferentes, ha restituido a las audiencias un rol activo y una mayor capacidad de rechazar o negociar los mensajes hegemónicos de los medios, principalmente como un correctivo a los enfoques críticos tradicionales como el de la economía política y el imperialismo cultural, los cuáles tienden

13 Por ejemplo, en relación a ciertas publicaciones teóricas y metodológicas que podríamos reconocer como aportaciones en Francia por autores teóricos culturalistas reconocidos como Michel de Certeau y Daniel Dayan (colega y coautor con E. Katz) y, además, porque son constantemente citados en revistas científicas francesas de acuerdo con la investigadora brasileña Ilusca Coutinho, se encuentran los trabajos de Nestor Canclini sobre las estrategias de comunicación propuestas para las culturas híbridas; los trabajos de Jesús Martín Barbero con respecto a los estudios de las mediaciones y su recurso metodológico del mediocentrismo; los estudios de Eliseo Veron, con sus aportes sobre la reflexión de los discursos sociales; los aportes de Jorge A. Gonzalez, con respecto al enfoque de frentes culturales; etc. En, Llusca Coutinho. 2001. "Estudos Culturais Latino-Americanos Despertam Interesse de Pesquisadores Franceses". Revista Pensamiento Comunicacional Latino-Americano. Vol. $2 \mathrm{~N}^{\circ}$ 3. Junio del 2001. p.3. 
a concebir de una manera simplista e ideologizada a los receptores como entes pasivos y manipulables.

Actualmente, las principales corrientes de este enfoque en Latinoamérica son las siguientes: 1). El uso social de los medios, propuesta de estudio que encabeza el hoy Profesor Investigador del Departamento de Estudios Socioculturales del Instituto Tecnológico de Estudios Superiores de Occidente (Iteso), en Guadalajara, México, el colombiano J. Martín Barbero; 2). El consumo cultural, propuesta de estudio desarrollada por el argentino-mexicano Nestor García Canclini, del Departamento de Educación y Comunicación de la Universidad Autónoma Metropolitana (UAM-X.), en México; 3). La recepción activa, propuesta de estudio desarrollada por el chileno Valerio Fuenzalida, del Centro de Indagación y Expresión Cultural y Artística de Chile (Ceneca) en Santiago; 4). Los Frentes Culturales e Identidades Complejas, corriente que precede Jorge A. González del Programa Cultural de la Universidad de Colima, México y, 5). El modelo de multimediaciones, que desarrolla Guillermo Orozco en el seno del Programa Institucional de Investigación en Comunicación y Prácticas Sociales (Priicom) de la Universidad Iberoamericana, en México.

En la centralidad cultural, que se origina desde los primeros años de la década de los ochentas, los cinco enfoques son compatibles con el enfoque amplio de estudios culturales y comparten con éste y entre sí, un buen número de supuestos y conceptualizaciones básicas; los estudios culturales asumen a la comunicación como práctica sociocultural definida por la producción del sentido.

Dentro de las principales corrientes de los estudios culturales, el estatuto de los estudios de las ciencias de la comunicación, como lo menciona Fuentes (1999: 63), las nociones de interdisciplinariedad o, incluso transdiciplinariedad, parecen quedar cortas.

\section{a). El Uso Social de los Medios.}

Dentro de esta corriente y, en términos generales dentro de los estudios de comunicación y cultura, es Jesús Martín Barbero uno de los principales teóricos e intelectuales en América Latina; Martín Barbero concibe a los medios de comunicación como productores sociales y enclaves de condensación e interacción de mediaciones humanas, de conflictos simbólicos e intereses políticos y económicos.

En el estudio de los usos sociales de los medios, Martín Barbero (1989: 1), evita la falacia de contraponer de manera simplista e ideologizada, los esfuerzos hegemónicos de las clases dominantes mediante la comunicación masiva y los procesos de resistencia, mediación y negociación de los sectores subalternos, rescatando lo central: lo popular.

Martín Barbero (2001: 88), emplea también el uso social de los medios para entender las nuevas condiciones de entrelazamiento entre lo social y lo político, en 
como se forma y desforma la opinión pública y en cómo se desarrollan los ejercicios de las nuevas formas de ciudadanía y democratización en América Latina.

Fundamentado inicialmente en las teorías gramscianas sobre la hegemonía, en la últimos años Martín Barbero (1996: 79-94), se ha apoyado de manera muy especial y profunda en la obra y en el bagaje teórico-conceptual de J. Habermas (principalmente en la obra normativa, de la opinión pública y, sobre todo, en la acción comunicativa ${ }^{14}$ ) para explicar de manera profunda que la receptividad del mensaje de la comunicación de masas no es ciertamente una recepción pasiva de la audiencia, sino que existe una articulación, cotidiana y permanente, con las rutinas del receptor, la comunidad, lo nacional y lo global.

Para Martín Barbero (1999: 7-21), la serie de mediaciones en la globalización comunicacional actual, han y están provocando hoy más que nunca en los receptores, desde las culturas tradicionales (precolombinas, negras y campesinas), nacionales (regionales y locales) y urbanas, un descentramiento cultural y, por consiguiente, fuertes transformaciones en los mapas culturales (desagregación y aislamiento social, fundamentalmente) de América Latina.

\section{b). El consumo cultural}

Como señalamos anteriormente, uno de los pocos investigadores especializados en los estudios sobre consumo cultural, audiencias y recepción en América Latina es el antropólogo Néstor García Canclini. Apoyado fuertemente en algunos teóricos que reelaboran la problemática del consumo cultural como Pierre Bourdieu, Manuel Castells, Mary Douglas y Michel de Certeau; García Canclini (1998: 17), concibe el estudio del consumo cultural como la mejor forma de analizar los procesos de recepción de la comunicación de masas.

En la construcción teórica de García Canclini (1990: 6), se toman en cuenta una gran variedad de factores que intervienen en los campos de estudio de la antropología, la sociología y las ciencias de la comunicación, entre los que

14 Retomando la idea de "construcción de mapas teóricos" que realiza Edgardo Albizu (1989) sobre la teoría de la acción comunicativa de Habermas, nos dice que éste último propone, montado en un predominio del punto de vista histórico donde encuentra conexión con la obra de Max Weber, el superar la abstracción metodológica de la teoría de la complejidad sistémica creciente (de Parsons y Luhmann, respectivamente), basado en el "estructuralismo genético" según el modelo de la psicología del desarrollo de Piaget y que asimila las tesis de 1), la sociología de la religión de Weber; 2), la teoría de la comunicación social de G. H. Mead y, 3), la teoría de la integración social de E. Durkheim, en un horizonte de temas y actitudes teórico-críticas provenientes de Marx, Lukács y la Escuela Crítica de Frankfurt. Desde nuestro punto de vista, es fundamentalmente ésta última integración (3) donde más apoya teórico encuentra Martín Barbero para desarrollar e ir consolidando hasta hoy en día la teoría de las mediaciones, tanto en sus figuras centrales (Horkheimer, Adorno, Marcuse) como en los laterales (Benjamín, Neumann y Kirchheimer); Para Martín Barbero, esto le es posible por las mediaciones que logra entre las teorías contemporáneas del lenguaje y la cultura, con cuyo auxilio, replanteará los conceptos de razón y de acción en los efectos que provoca el uso social de los medios masivos de comunicación. 
destacan la racionalidad de los intercambios económicos y culturales (convivencia y conflicto) en los dos primeros campos y, el uso de los bienes de consumo cultural como transmisores de información y significado en el último.

García Canclini (1991: 2) define al consumo como el conjunto de procesos socioculturales en que realizan la apropiación y los usos de los productos. Esta ubicación del consumo como parte del ciclo de producción y circulación de los bienes, le permite hacer visible aspectos más complejos y afines que los encerrados en la mera [compulsión consumista] y economista del término: la recepción, apropiación y las audiencias o usos.

De manera particular, García Canclini (1991:4), define el consumo cultural como el conjunto de procesos de apropiación y usos de productos en los que el valor simbólico prevalece sobre los valores de uso y de cambio, o donde al menos estos últimos se configuran subordinados a la dimensión simbólica. Para ocuparse del estudio detallado del consumo cultural, García Canclini instrumenta seis modelos teóricos metodológicos que provienen de diversas disciplinas. Cada uno de los seis modelos son necesarios para explicar aspectos del consumo, aún cuando, según García Canclini, ninguno de ellos es autosuficiente ni se han establecido principios teórico-metodológicos para su conexión.

1). Modelo 1: El consumo es el lugar de reproducción de la fuerza de trabajo y de expansión del capital. De acuerdo con este modelo, todas las prácticas de consumo pueden entenderse como medios para renovar la fuerza laboral de los trabajadores y ampliar las ganancias de los productores. En esta perspectiva, en la que Canclini se apoya fundamentalmente en la obra de Michel de Certeau, no es la demanda la que suscita la oferta del consumo de bienes sino la tendencia expansiva de capital para ampliar sus ganancias. Por eso, el propósito de implementar el modelo es el análisis de la dimensión cultural del consumo y las formas de apropiación y uso donde es necesario conocer como se articula la racionalidad de los productores con la racionalidad de los consumidores.

2). Modelo 2: El consumo es el lugar donde las clases y los grupos compiten por la apropiación del producto social. Aquí, García Canclini instrumenta el presente modelo a partir de concebir el consumo como conflicto entre clases, originado por la creciente y desigual participación en la estructura productiva, las cuáles se continúan en la distribución y apropiación de los bienes. Rectificando el modelo anterior (en la visión vertical del consumo), este modelo considera al consumo como un escenario de disputa por aquello que la sociedad produce y las maneras en como debe usarlo (apropiación de los bienes).

3). Modelo 3: El consumo como lugar de diferenciación social y distinción simbólica entre grupos. Apoyado en los estudios de Pierre Bourdieu, García 
Canclini instrumenta el modelo para analizar la masificación de la mayoría de los bienes que genera la modernidad y las diferencias que se producen cada vez más no por los objetos o bienes materiales que se poseen sino por las formas en que son utilizados y en las maneras en que se transmutan en signos los objetos que se consumen: por las diferencias simbólicas.

4. Modelo 4: El consumo como sistema de integración y comunicación. El modelo sirve para estudiar y entender el consumo cultural como intercambio y distinción de significados y valores comunes dentro de un sistema de comunicación donde cierta clase de bienes (la música, la ropa, etc.) conectan y vinculan a todas las clases sociales aunque la apropiación sea diversa.

5). Modelo 5: El consumo como escenario de la objetividad de los deseos. En esta opción, García Canclini implementa este modelo con el objeto de analizar a profundidad las modalidades que el deseo adopta frente a las proliferantes ofertas del consumo; según Canclini, el deseo no puede ser ignorado cuando se analizan las formas de consumo pues el deseo es un ingrediente frecuentemente utilizado por el diseño, la producción y la publicidad de los objetos.

6). Modelo 6: El consumo como proceso ritual. De acuerdo con este modelo, que plantea el postulado teórico de Mary Douglas, ninguna sociedad puede soportar demasiado tiempo la incertidumbre de los significados, de ahí que se creen los rituales y la necesidad de su estudio. Los rituales, explica Canclini retomando a Douglas, sirven para contener el curso de los significados y hacer explícitas las definiciones públicas de lo que el consenso general juzgue valioso. Por ello, en la teoría del modelo No. 6, el bien material es definida como accesorios rituales y el consumo como el proceso ritual cuya función primaria consiste en darle sentido al flujo de acontecimientos del consenso social.

\section{c). La Recepción Activa}

El Dr. Valerio Fuenzalida es uno de los teóricos Latinoamericanos que mayor impulso práctico (estudios e investigaciones publicadas) a generado en pro de la capacidad crítica de las audiencias en la recepción del mensaje. Las propuestas y la experiencia de Fuenzalida y su grupo de trabajo del Ceneca han contribuido significativamente al desarrollo de los esfuerzos de la educación y la cultura para la recepción en América Latina.

Fuenzalida afirma (1989: 32), que la influencia grupal es sumamente importante en la construcción del sentido que las personas le confieren al mensaje. En este sentido, la familia, la mediación televisiva y la interacción con grupos organizados de todo tipo, ejercen una influencia decisiva en los hábitos y preferencias 
de información en la recepción del mensaje y en la elaboración de las significaciones socioculturales del individuo.

Para el investigador chileno, lo que muestran en definitiva los estudios de recepción es que el receptor socio-cultural y el contexto de la recepción televisiva son constituyentes activos del proceso de Comunicación. No son «recipientes» o «variables intervinientes» (Fuenzalida, 1985: 66). Frente al significado intencional querido por el emisor, frente al significado inmanente al texto detectado por el análisis semiótico, también existe lo que Fuenzalida llama “...el significado concreto y existencial, es decir, lo construido por el receptor en interacción con el mensaje y con su emisor..."; Hay, pues, una producciónde significación en la recepción; la producción del significado no se agota en el trabajo del emisor ni en la elaboración semiótica.

Para Fuenzalida, lo anterior también implica reconocer la historización del proceso de recepción y de la influencia cultural de la televisión. Para él, el fuerte descuido de la investigación por la recepción, proviene de una epistemología deshistorizada acerca de la recepción y acerca del contexto cultural; la recepción había sido concebida según los modelos lineales-monocausales que el positivismo del siglo pasado aplicó a los fenómenos naturales.

En esa concepción, la recepción era un producto o resultado que podía ser previsto y deducido a partir de los supuestos deterministas causales manipulados por el emisor. La historización de la recepción y de la influencia cultural de la recepción activa propuesta por Valerio Fuenzalida (1989: 6) nos muestra, en cambio, que la causalidad lineal y omnipotente no se verifica, que "ocurre un proceso de recepción constructivista, dialéctico y conflictivo ... y que este mismo contexto socio-cultural heterogéneo penetra semióticamente los textos televisivos, manifestándose en una heterodiscursividad...”.

\section{d). Los Frentes Culturales e Identidades Complejas}

Como mencionamos anteriormente, el Dr. Jorge Alejandro González, ha dedicado en realidad poco trabajo a los estudios de la comunicación (Temer, 2001:2); sin embargo, tiene significativos aportes y desarrollo de técnicas, métodos y metodologías en el campo de los estudios culturales, los cuáles se orientan en ".. obtener una respuesta de conocimiento que ayude a resolver un problema práctico ...”. Para Jorge González, la construcción de los sentidos y las significaciones sociales a través de los medios masivos de comunicación se convierte, hoy en día, en un campo de batalla por monopolizar las visiones de las necesidades, las identidades y los valores sociales.

En este sentido, la cultura para Jorge González (1996: 41) sirve para diferenciar, clasificar y operar las diferentes visiones del mundo. En relación con esta, la comunicación la entiende como el proceso de construcción, de[construcción] y re[construcción] de múltiples efectos de sentido, a partir del lugar que los 
interlocutores ocupan en la estructura social y en relación con el dominio de un campo ideológico preciso.

Para González (1994:102), el melodrama televisivo es el mejor ejemplo identificado de esta relación: "La telenovela, tal como se ha generado en México, es un espacio fractal donde se lucha por la definición del valor simbólico, no sólo del formato, sino de las formas sociales que ella pone en escena y que largamente exceden los límites del texto y su textura..." ${ }^{15}$.

\section{e). El Modelo de las Multimediaciones}

El principal exponente de este enfoque es el Dr. Guillermo Orozco. Ello ha sido posible por el desarrollo del modelo que identifica y analiza a fondo una serie de multimediaciones en la recepción activa del mensaje por parte del individuo. De acuerdo con Orozco (citado por Lozano, 1996:208-110), el modelo de las mediaciones en la recepción televisiva se compone por las siguientes mediaciones:

1.) Las mediaciones cognoscitivas (lo afectivo, lo racional y lo valorativo); 2). Las mediaciones culturales (presentes en las interacciones sociales y televisivas); 3). Las mediaciones situacionales (étnica, sexual, cultural, socioecómica y geográfica); 4). Las mediaciones institucionales (todas las instituciones sociales con las que el sujeto interactua) y, 5). Las mediaciones videotecnológicas (en sus diversas significaciones con la realidad: la creación de noticias, la presencia del receptor, la construcción de la verdad y la apelación emotiva).

Para Orozco, la apropiación del mensaje televisivo por parte del receptor, se produce antes, durante y después de la exposición a ellos, debido al complejo funcionamiento de estas mediaciones en cada individuo.

Como producto de la implementación del modelo en investigaciones empíricas, Orozco concluye que la actividad del individuo y, en general de las audiencias frente al televisor, las lleva a producir significados culturales diversos y no sólo a reproducir los que le llegan directamente de la mediación: "Las audiencias son activas, pero sobre todo creativas. Producen sentido en su interacción social; los límites a esa producción no están dados sólo por razones individuales. Más bien están dados a la creatividad en sí, en un escenario socialmente específico..."16.

Actualmente, el Dr. Guillermo Orozco se encuentra trabajando, a partir del modelo de las multimediaciones, diversas perspectivas epistemológicas para el

15 Jorge A. González \& Jesús Galindo: Metodología y Cultura, Consejo Nacional para la Cultura y las Artes. México, D.F. 1994.

16 Guillermo Orozco. (1990/91). "La Mediación en Juego: Televisión, Cultura y Audiencia". Revista Comunicación y Cultura, No 30 . Universidad de Guadalajara. P. 122; Citado en: Lozano, José Carlos. 1996. Op. Cit. p. 211. 
análisis de la interacciones de la televidencia con el medio televisivo en el seno del Priicom de la Universidad Iberoamericana y en coordinación con el Departamento de Estudios de la Comunicación Social de la Universidad de Guadalajara ${ }^{17}$.

\section{Bibliografía:}

- ACEVEDO, Alberto: Cultura y Comunicación. La Relación entre el Capital Cultural, el Consumo Nacional y la Recepción Televisiva. Ed. Universidad de Sonora. Colección Textos Académicos, 2001.

- AGUIRRE, Jesús María: El Perfil Ocupacional de los Periodistas en Caracas. Universidad Católica Andrés Bello. Colección Ayacuá No 1. Caracas, 1992

- ALBIZU, Edgardo: Teoría del Actuar Comunicativo de Jurgen Habermas. Revista Diálogos de la Comunicación. Federación Latinoamericana de Facultades de Comunicación. Lima, $\mathrm{N}^{\circ}$ 20. Octubre, 1990

- BELTRÁN, Luis R: El Sueño en la Nevera. Revista Latinoamericana de Comunicación Chasqui. $N^{o}$ 71. Junio, 2000. Premisas, Objetos y Métodos Foráneos en la Investigación sobre Comunicación en América Latina. En, Moragas, M. Sociología de la Comunicación de Masas. I. Escuelas y Autores. Ed. Gustavo Gili. 4ta. Edición. Barcelona, 1994. Communication Research in Latin America: The Blind Folded Inquirí?. ICC. IAMCR. Leipzig, September 17th, 1974.

- BELTRÁN Salmón, Luis: Investigación sobre Comunicación en Latinoamérica: Inicio, Trascendencia y Proyección. Universidad Católica Boliviana y Plural Editores, 2000.

- BELLO, Gilberto; BUENAVENTURA, Juan; PÉREZ, Gabriel: Concepción de la Comunicación y Crisis Teóricas en América. Revista Diálogos de la Comunicación. Federación Latinoamericana de Facultades de Comunicación. Lima, $\mathrm{N}^{\circ}$ 20. Octubre, 1990.

- BOURDIEU, Pierre: Respuestas por una Antropología Reflexiva. Ed. Grijalvo. México, 1995. El Oficio del Sociólogo. Ed. Siglo XXI; México, D.F., 1975.

- CRAIG, R: Communication Theory as a Field. Ed. Department of Communication, University of Colorado. Boulder, USA, 2000.

17 Guillermo Orozco (compilador), varios autores. Lo viejo y Lo Nuevo: Investigar la Comunicación en el siglo XXI. Ed. de La Torre. Madrid. 2000. En esta compilación, se reúne fundamentalmente el trabajo del grupo de profesores/investigadores del Departamento de Estudios de la Comunicación Social de la Universidad de Guadalajara, México. La idea, es reflejar, a través de diversos artículos, las diferentes trayectorias académicas, los intereses y los modos variados de plantear y realizar investigación en comunicación en este importante núcleo de investigadores latinoamericanos donde sobresalen Jesús Martín-Barbero, Raúl Fuentes Navarro, Sarah Corona, Enrique Sánchez Ruíz, Guillermo Orozco, Martha Renero, Armando Marín, entre otros. 
- DE FLEUR \& BALL ROKEACH: Teorías de la Comunicación de Masas. Paidós Comunicación. 6ta Reimpresión. México, 1991.

- EMANUELli, Paulina B: Investigación de la Comunicación en Argentina. Reflexiones sobre la Investigación Crítica. Revista Andaluza de Comunicación Ámbitos. Universidad de Sevilla. No. 2. Junio, 1999.

- ESTEINOU MADRID, Javier: El Olvido de Armand Mattelard por la Academia de Comunicación Mexicana. Revista Pensamiento Comunicacional Latinoamericano. Universidad Metodista de San Paulo. Volumen 1. No. 1: Octubre/ Noviembre/Diciembre, 2000. Globalización, Medios de Comunicación y Cultura en México a Principios de Siglo XXI. Revista Andaluza de Comunicación Ámbitos. Universidad de Sevilla. No. 5. Segundo Semestre del 2000, 2000/a. Siglo XXI. Leyes del Mercado y Nuevo Proyecto de Comunicación en América Latina. Facultad de comunicación Social y Periodismo, Santa Fe de Bogotá, Colombia. Septiembre, 2000/b. Sociedad Moderna y Medios de Comunicación, Ed. UAM. México, 1995. Televisión Pública y Desarrollo Cultural, Colección Reflexiones Universitarias No. 6, UAM, 1994. La Cultura y la Comunicación Nacionales en los Tiempos del Libre Mercado, fundación Manuel Buendía y Presidencia de la República. México, 1993. Los Medios de Comunicación y la Construcción de la Hegemonía. UAM. México, D.F., 1992. La Televisión Mexicana ante el Nuevo Modelo de Desarrollo Neoliberal. Ed. Fundación Manuel Buendía. México. 1991. Economía Política y Medios de Comunicación: Acumulación, Ideología y Poder. Ed. Trillas, México.

- FADUL, Anamaria, 1985: Las Ciencias Sociales en la Enseñanza y la Investigación de la Comunicación. Revista Diálogos de la Comunicación. Federación Latinoamericana de Facultades de Comunicación. Lima, No. 32. Junio, 1994.

- FUENTES NAVARRO, Raúl: La Investigación de la Comunicación en América Latina: Condiciones y Perspectivas para el Siglo XXI. Revista Diálogos de la Comunicación. Federación Latinoamericana de Facultades de Comunicación. Lima, N. 56. Octubre, 1999. La Emergencia de un Campo Académico: Continuidad Utópica y Estructuración Científica de la Investigación de la Comunicación en México. Iteso/Universidad de Guadalajara. Guadalajara, 1998. Retos Disciplinarios y Postdisciplinarios para la Investigación de la Comunicación. Revista Comunicación y Sociedad. N ${ }^{\circ}$. 31. Universidad de Guadalajara, México. Septiembre-Octubre, 1997. El Estudio de la Comunicación desde una Perspectiva Sociocultural en en América Latina. Revista Diálogos de la Comunicación. Federación Latinoamericana de Facultades de Comunicación. Lima, №. 32. Marzo, 1994. El Diseño Curricular en la Formación Universitaria de Comunicadores Sociales para América Latina. Revista Diálogos de la Comunicación. Federación Latinoamericana de Facultades de Comunicación. Lima, No. 17. Marzo, 1989. 
- FUENZALIDA, Valerio: La Influencia Cultural de la Televisión. Revista Diálogos de la Comunicación. Federación Latinoamericana de Facultades de Comunicación. Lima, No. 17. Marzo, 1989. Televisión y Recepción Activa. CENECA. Santiago, 1985.

- GAETE MARTÍNEZ, Sergio:Verificadores de Audiencia: ¿Son confiables los Estudios de Sintonía? Revista Latinoamericana Chasqui. №. 69. Mayo, 2000.

- GALINDO CÁCERES, Jesús: Oralidad y Cultura. La comunicación y la Historia como Cosmovisiones y Prácticas Divergentes. Revista Andaluza de Comunicación Ámbitos. Universidad de Sevilla. No. 5. Segundo Semestre del 2000, 2000. Política, Cultura y Comunicación. Ed. Universidad Iberoamericana. León, Gto., 1995.

- GARCÍA CANCLINI, Néstor: La Globalización en Pedazos: Integración y rupturas en la Comunicación. Revista Diálogos de la Comunicación. Federación Latinoamericana de Facultades de Comunicación. Lima, No. 51. Octubre. 1998. Los Estudios Sobre comunicación y Consumo. El Trabajo Interdisciplinario en Tiempos Neoconservadores. Revista Diálogos de la Comunicación. Federación Latinoamericana de Facultades de Comunicación. Lima, Nº 32. Marzo, 1994. El Consumo para Pensar. Revista Diálogos de la Comunicación. Federación Latinoamericana de Facultades de Comunicación. Lima, Nº 30. Octubre, 1993.

- GARCÍA GUTIÉRREZ, Antonio: Notas Sobre Procesos Reflexivos y Funciones en los Nuevos Especialistas de Información: Aproximación a los Perfiles Formativo e Investigador. Revista Andaluza de Comunicación Ámbitos. Universidad de Sevilla. No. 3-4. Julio, 2000.

- GIDDENS, Anthony: La Teoría Social, Hoy. Ed. Alianza/CONACULTA. México, 1991.The Constitution of Society: Outline of the Theory Structuration. University of California Press, Berkeley, 1984.

- GIRÁLDEZ CALDERÓN, Miguel: Reflexiones sobre la Teoría Crítica y el Nuevo Ecosistema Comunicativo. Revista Andaluza de Comunicación Ámbitos. Universidad de Sevilla. No. 1. Diciembre, 1998.

- GONZÁleZ, Jorge A: La Cultura en México. Ed. Universidad de Colima, México. México, 1996. Metodología y Cultura. Ed. Consejo Nacional para la Cultura y las Artes. México, D.F., 1994.

- GONZÁLEZ MOLINA, Gabriel: Organización, Burocracia y Profesión. Determinismo Institucional de las Comunicaciones Sociales. En Enrique Sánchez Ruiz (Comp.). La Investigación de la Comunicación en México. Ed. Universidad de Guadalajara, México, 1987.

- GUTIÉRREZ, María: La Comunicación en América Latina. Informe de México. Revista Latinoamericana de Comunicación Chasqui. №. 74. Junio, 2001. 
- LASSWELL, H. D.: Estructura y Función de la Comunicación en la Sociedad. En, Moragas, Miguel de, Sociología de la Comunicación de Masas. Ed. Gustavo Gili. 2da. edición. Barcelona, 1984. The Language of Politics. Henry Stewart Inc. East Aurora. (New York), 1949. Propaganda and Promotional Activities. University of Minnesota Press. Minneapolis, 1935. Propaganda Tecniche In The World War. Alfred A. Knopf Press, London, 1927.

- LAZARSFElD, P.F.: El Pueblo Elige. Cómo Decide el Pueblo en una Campaña Electoral. Ediciones 3, Buenos Aires, 1948. Radio Research, Duell, Sloan \& Pearce. New York, 1941. Radio \& The Printed Page, Duell, Sloan \& Pearce. New York, 1940.

- LACALLE ZALDUENDO, Charo: El Profesor Wolf. Revista Análisis. Universidad Autónoma de Barcelona. Departamento de Ciencias de la Comunicación. No. 20. Junio, 1997.

- LEISS, William: On the Vitality of Our Discipline. New Applications of Communication Theory: The 1990 Southam Lecture. Simon Fraser University. N.Y., 1996.

- LEÓN, Gustavo: Comunicación y Sociedad de las Organizaciones. Notas Sobre la Teoría de la Acción de Talcott Parsons. En, León, Trujillo, Castillo, Covarrubias y Ramírez. La Comunicación: un Campo de Estudio Multidisciplinar. Universidad de Sonora, Hermosillo, 2001. Situación Actual y Tendencias Futuras de la Comunicación Organizacional en México. Revista Tópicos de la Comunicación. Departamento de Ciencias de la Comunicación de la Universidad de Sonora. No. 0 Noviembre-Diciembre del 2000, 2000.

- LOZANO RENDÓN, José C: Espectacularización en la Cobertura Informativa de las Elecciones Mexicanas a la Presidencia. Revista Comunicación y Sociedad. Facultad de Comunicación de la Universidad de Navarra. Volumen XIV. $\mathrm{N}^{\circ}$. 1 Junio, 2001. La Investigación sobre la Comunicación Internacional en México. Revista Razón y Palabra. Instituto Tecnológico de Estudios Superiores de Monterrey. $\mathrm{N}^{\circ}$. 7. Año 2. Junio-Agosto, 1997. Teoría e Investigación de la Comunicación de Masas. Pearson Al Hambra Mexicana. México, 1996. Temas y Fuentes en la Información Nacional de la La Jornada, El Norte y El Porvenir: Un Análisis desde la Sociología de las Organizaciones de Medios. Ponencia. II Congreso Latinoamericano de Investigadores de la Comunicación. Guadalajara, México. Junio, 1994.

- LUHMANN, N: La Realidad de los Medios de Masas. Ed. Anthropos/Universidad Iberoamericana. Barcelona, 2000.

- MALTA DE BARROS, Luis: Las Políticas Nacionales de Comunicación son Hoy Más Necesarias que Nunca. Entrevista con Luis Ramiro Beltrán. Revista Pensamiento Comunicacional Latinoamericano. Universidad Metodista de San Paulo. Volumen 1. Nº. 1: Octubre/Noviembre/Diciembre, 2000. 
- MATTELART, Armand: La Comunicación Masiva en el Proceso de Liberación. Ed. Siglo XXI; 14ª Edición, México, D.F., 1998. Utopía y Realidades del Vínculo Global. Para una Crítica del Tecnoglobalismo. Revista Diálogos de la Comunicación. Federación Latinoamericana de Facultades de Comunicación. Lima, No. 50. Junio, 1997. La Cultura como Empresa Multinacional. Ed. Era, México. D.F., 1994. Prefijuración de la Ideología Burguesa; Lectura Ideológica de Una Obra de Malthus. Ed. Schapire, Buenos Aires, Argentina, 1975. La Ideología de la Dominación en una sociedad Dependiente. Ed. Sinos, Buenos Aires, Argentina, 1972. Los Medios de comunicación de Masas. La Ideología de la prensa Liberal Chilena. Universidad Católica de Chile, Santiago de Chile, 1970.

- MARQUES DE MELO, José: ELACOM. Génesis, Crecimiento, Perspectivas. Revista Pensamiento Comunicacional Latinoamericano. Universidad Metodista de San Paulo. Volumen 1. N . 1: Octubre/Noviembre/Diciembre, 1999. Desafíos Actuales de la Comunicación. Reflexiones en Torno a la Experiencia Brasileña. Revista Diálogos de la Comunicación. Federación Latinoamericana de Facultades de Comunicación. Lima, No . 19. Enero, 1990.

- MARTÍN BARBERO, Jesús: Reconfiguraciones Comunicativas de lo Público. Revista Análisis. Universidad Autónoma de Barcelona. No. 26. Junio, 2001. El Futuro que Habita la Memoria. Revista Pensamiento Comunicacional Latinoamericano. Universidad Metodista de San Paulo. Volumen 2. No. 3: Abril/ Mayo/Junio, 2001/a. Las Transformaciones del Mapa Cultural: Una Visión desde América Latina. Ámbitos, Revista Andaluza de Comunicación. Universidad de Sevilla. Nº. 2. Junio, 1999. Secularización, Desencanto y Reencantamiento Mass Mediatico. Revista Diálogos de la Comunicación. Federación Latinoamericana de Facultades de Comunicación. Lima, N. 50. Marzo, 1997. Comunicación: El Desentramiento de la Modernidad. Revista Análisis. Universidad Autónoma de Barcelona. Departamento de Ciencias de la Comunicación. №. 19. Junio, 1996. Globalización Comunicacional y Desentramiento Cultural. Revista Diálogos de la Comunicación. Federación Latinoamericana de Facultades de Comunicación. Lima, №. 41. Diciembre, 1995. Pensar en la Sociedad desde la Comunicación. Un Lugar Estratégico para el Debate a la Modernidad. Revista Diálogos de la Comunicación. Federación Latinoamericana de Facultades de Comunicación. Lima, No. 32. Marzo, 1994. Euforia Tecnológica y Malestar en la Teoría (Diálogo abierto con el Profesor Mauro Wolf). Revista Diálogos de la Comunicación. Federación Latinoamericana de Facultades de Comunicación. Lima, No . 28. Septiembre, 1992.Teoría-Investigación-Producción en la Enseñanza de la Comunicación. Revista Diálogos de la Comunicación. Federación Latinoamericana de Facultades de Comunicación. Lima, No. 28. Marzo, 1992. Comunicación, Campo Cultural y Proyecto Mediador. Revista Diálogos de la Comunicación. Federación Latinoamericana de 
Facultades de Comunicación. Lima, No. 26. Septiembre, 1991. Crisis en los Estudios de Comunicación y Sentido de una Reforma Curricular. Revista Diálogos de la Comunicación. Federación Latinoamericana de Facultades de Comunicación. Lima, №. 19. Junio, 1989. De los Medios a las Mediaciones: Comunicación, Cultura y Hegemonía. Ed. Gustavo Gili. México, D.F.

- MARTÍN DÍEZ, María A., 1987: Latinoamérica, En la Comunicación Mundial. Ámbitos, Revista Andaluza de Comunicación. Universidad de Sevilla. Nº. 3-4. Junio, 2000.

- MCQUAIL, Denis: Introducción a la Teoría de la Comunicación de Masas. Paidós Comunicación. 2da. Reimpresión. Buenos aires, 1989.

- MONTERO SÁNCHEZ, María: Mundialización y Construcción de la Opinión Pública. Revista Análisis. Universidad Autónoma de Barcelona. Departamento de Ciencias de la Comunicación. Nº. 26. Junio, 2001.

- MORAGAS SPA, Miguel: Las Facultades de Comunicación en el Umbral de la Era de Internet. Revista Latinoamericana de Comunicación Chasqui. № 72. Diciembre, 2000. Las Ciencias de la Comunicación en la Sociedad de la Información. Revista Diálogos de la Comunicación. Federación Latinoamericana de Facultades de Comunicación. Lima, No. 49. Junio, 1997. Sociología de la Comunicación de Masas. I. Escuelas y Autores. Ed. Gustavo Gili. 4ta. Edición. Barcelona, 1994.

- MORERA, Luis: Comunicación Institucional. Como Solucionar los Problemas en un Banco. Revista Latinoamericana de Comunicación Chasqui. Nº 72. Marzo, 2001.

- MURCIA SERRANO, Inmaculata: De Foucault a Chomsky: La Teoría del Poder y los Medios de Comunicación. Revista Gittcus. Universidad de Sevilla. Año III. No. 10. Junio, 2000.

- PARÉS MAICAS, Manuel: Herbert Schiller, In Memoriam. Revista Análisis. Universidad Autónoma de Barcelona. Departamento de Ciencias de la Comunicación. N N $^{\circ}$. 24. Junio, 2000.

- PINEDA DE ALCÁZAR, Migdalia: Los Paradigmas de la Comunicación: Nuevos Enfoques Teóricos-Metodológicos. Revista Diálogos de la Comunicación. Federación Latinoamericana de Facultades de Comunicación. Lima, No 60. Octubre, 2000.

- QUIROGA, Sergio R.: Latinoamérica, Modelos y Diálogo Social. Revista Pensamiento Comunicacional Latinoamericano. Universidad Metodista de San Paulo. Volumen 1. №. 2: Enero/Febrero/Marzo, 2000.

- SÁNCHEZ RUIZ, Enrique: Las Industrias Culturales Latinoamericanas en Tiempos de Globalización. Algunas tesis. Revista Pensamiento Comunicacional Latinoamericano. Universidad Metodista de San Paulo. Volumen 1. No. 1: Octubre/Noviembre/Diciembre, 2000. Algunos Retos para la Investigación Mexicana de la Comunicación. Una Reflexión Personal. Revista Sociedad y Comu- 
nicación N ${ }^{\circ}$. 30. Universidad de Guadalajara, México, 1997. Medios de Difusión y Sociedad. Notas Críticas y Metodologías. CEIC/Universidad de Guadalajara, México, 1992.

- SERRANO, Manuel Martín: Análisis Metódico de la Verdad en Comunicación. Revista Diálogos de la Comunicación. Federación Latinoamericana de Facultades de Comunicación. Lima, Nº. 20. Octubre, 1990.

- SOLÍS, Beatriz: Nuevos Parámetros en la Investigación de las Políticas Públicas de Comunicación. Revista Diálogos de la Comunicación. Federación Latinoamericana de Facultades de Comunicación. Lima, N. 56. Octubre, 1999.

- TEMER, Ana C.: Forjando as Bases Teóricas do Pensamento Comunicacional Latino-Americano. Entrevista a Jorge Alejandro González (Universidad de Colima, México). Revista Pensamiento Comunicacional Latinoamericano. Universidad Metodista de San Paulo. Volumen 2. No. 3: Abril/Mayo/Junio, 2001.

- THOMPSON, J. B.: Ideología y Cultura Moderna. La Teoría Social Crítica en la Era de la Comunicación Masiva. UAM. México, D.F. 4ta. Edición, 1998.

- TORRICO, VILlANUEVA, Eric: Eventos. Cochabamba fue Sede de la Más Grande Reunión Académica sobre Comunicación. Bolivia Organizará el VI Congreso Latinoamericano de Investigadores de la Comunicación, 2000.

- VASALlO DE LÓPEZ, María I: La Investigación de la Comunicación: Cuestiones Epistemológicas, Teóricas y Metodológicas. Revista Diálogos de la Comunicación. Federación Latinoamericana de Facultades de Comunicación. Lima, No. 56. Octubre, 1999. Por un Paradigma Transdiciplinar para el Campo de la Comunicación. V Ibercom. Porto, Brasil, 1998. Estado de las Investigaciones en Comunicación en Brasil. Edicom. Brasil, 1997.

- VELA MONTERO, José: Los Estudios de la Audiencia: Una Visión Crítica desde la Economía Política. Revista Ámbitos No. 5; Sevilla, $2^{\circ}$ Semestre del 2000, 2000.

- WOLF, Mauro: Los Emisores de Noticias en la Investigación sobre Comunicación Zer, Revista de Estudios de Comunicación. Universidad del País Vasco. No. 3. Noviembre, 1997. Desarrollos Teóricos en la Communication Research. Revista Diálogos de la Comunicación. Federación Latinoamericana de Facultades de Comunicación. Lima, $\mathrm{N}^{\circ}$. 20. Octubre, 1990. La Investigación de la Comunicación de Masas. Crítica y Perspectivas. Ed. Paidós Ibérica, Barcelona, España, 1987. 